\title{
CHRISTCHURCH SEISMIC HAZARD PILOT STUDY
}

\author{
J. B. Berril1, R. O. Davis² and I. F. McCahon ${ }^{3}$
}

\begin{abstract}
SUMMARY
A pilot zoning study has been carried out for ground shaking hazard in the city of Christchurch, using the grade- 3 procedures of the draft manual on seismic zonation for geotechnical hazards, being developed by Technical Committee TC-4 of the ISSMFE. Because of limited site data, we were not able to produce a complete zoning map for the city, but ground motions were estimated at six distinct sites for which borehole data was available, and this provided a good test for the procedures of the manual.

The city of Christchurch is situated on nearly $1 \mathrm{~km}$ of volcanic rock and alluvial sediments overlying greywacke basement, on the edge of the main seismic region of New Zealand. In addition to being an interesting site from the point of view of ground shaking, there are also liquefaction and slope stability hazards in the alluvial and beach sands found throughout the city, and in the recent loess deposits mantling the adjacent Port Hills.

In the pilot study of ground shaking hazard, a seismicity model for the central South Island region published recently by Elder et al. (1991) was combined with the attenuation model of Kawashima et al. (1984) recommended in the draft manual, to estimate rock motion at Christchurch, described by its acceleration response spectrum. Transfer functions were computed for the site response to estimate motions at the six selected sites using the Thomson-Haskell method. The results were highly sensitive to details of the upper $30 \mathrm{~m}$ or so of the soil profile. In the local context, the large disparity between our estimates of ground shaking at Christchurch and those implicit in the draft revision of NZS 4203 are disturbing. According to our study the draft code underestimates shaking by about a factor of two or more.
\end{abstract}

\section{INTRODUCTION}

Under the chairmanship of Prof. K. Ishihara, Technical Committee TC-4 of the International Society for Soil Mechanics and Foundation Engineering (ISSMFE) has undertaken to write a manual on seismic zoning for geotechnical hazards. The Japan Working Group of TC-4 has produced a draft manual, entitled Seismic Zoning on Geotechnical Hazards, and other members of the committee have been invited to make pilot zoning studies in their own countries, using the draft manual. The results of these studies were presented at a Workshop held in Lisbon in July 1992, immediately after the 10th World Conference on Earthquake Engineering, and editing of the final manual was discussed in the light of experiences with the pilot studies.

The manual addresses the three main geotechnical problems in zoning for seismic hazards: ground shaking, liquefaction and landsliding. In each case, guidelines for three grades of study

${ }^{1,2}$ Dept of Civil Engineering, University of Canterbury, Christchurch, New Zealand ( ${ }^{1}$ Fellow).

3 Soils and Foundations Ltd, Consulting Engineers, Christchurch, New Zealand are given, depending on the information available about the seismicity of the region and about the local soil conditions.

This paper describes a pilot study in which we address the problem of zonation for ground shaking for the city of Christchurch, a city founded on deep sediments in an earthquakeprone area using the most advanced, grade 3 , methods. These comprise the probabilistic estimation of ground shaking as a function of return period, starting with a seismicity model for the region and an attenuation model to estimate rock motions and then using a one-dimensional Thomson-Haskell model to allow for the effect of the $700 \mathrm{~m}$ thick soil column beneath the city.

The results are presented in the form of a map delineating six zones corresponding to six different types of soil condition, together with acceleration response spectra for each zone. Elastic acceleration response is chosen as the measure of ground shaking following New Zealand design practice; the spectra are estimated for 5 percent damping and a 150-year return period consistent with the N.Z. structural design code. Base shear coefficients can be obtained as a function of undamped natural period and design ductility factor, using simple rules from the code commentary. 
This study builds upon earlier work by Elder et al.(1991) evaluating seismic hazard in Christchurch, and draws heavily on their seismicity model and on their catalogue of soil conditions as well as on previous work by the authors for specific sites in the city. Advances of this work over the earlier study include the estimation of uniform risk spectra period by period in the range of $0 \leq T \leq 3 \mathrm{~s}$ ( $\mathrm{T}$ is natural period) rather than the simple scaling of a spectrum of fixed shape, allowance for a characteristic event on the Alpine Fault (the major fault in the region) and an exploration of the sensitivity and shortcomings of the one-dimensional site-effects model.

Since the aim here is to test the methods of the draft TC-4 manual the scope of the study has been limited to certain sections of the inner city for which good site information was available. But the mixed and quite variable estuarine and fluvial soil conditions in this area offer sufficient variety for an adequate testing of the zonation methods. Spectra were also estimated for an outlying site, typical of conditions further inland from the centre of the city and away from the estuarine soils found under the central and south eastern parts of the city.

The computations are carried out in two steps. First, rock motions beneath the city are estimated, using the classical seismic hazard computation of Cornell (1968), with the local seismicity model of Elder et al. (1991) and the attenuation model of Kawashima et al. (1984) recommended in the TC-4 draft manual. Then transfer functions are estimated for the representative sets of soil conditions, and applied to the rock motions to obtain surface motions for the six representative soil sites. In the remainder of this report, we focus principally on the problems encountered in the study, and on deviations from or additions to the methods of the draft manual. The general method is not described in detail since it has already been described many times elsewhere [see, for example, Cornell (1968), McGuire (1974), Berrill (1985a), Matuschka et al. (1985)].

\section{GEOLOGY OF REGION}

New Zealland lies astride the Pacific and Indian plates, which approach one another obliquely at a rate of about $50 \mathrm{~mm} / \mathrm{y}$ at the latitude of Wellington. The north east - south west treading boundary is marked by a pattern of major faults, shown in Figure 1. The tectonics are quite complex, with subduction of the Pacific plate beneath the North Island and northern part of the South Island, a zone of collision between two sections of continental crust in the central South Island, and subduction again in the far south but in the opposite sense, with the Indian plate being subducted beneath the Pacific plate. Epicentres of large earthquakes during the past 150 years are also shown in Figure 2. The rate of activity is similar to that of California, although for the past 40 to 50 years the seismicity has been much less than in the preceding 50 years. The principal fault in the South Island is the Alpine Fault, which is remarkable for its historical inactivity. The satellite photo in Figure 3 shows the central section of the South Island, with the Alpine Fault standing out to the west of the Southern Alps and the quaternary sediments of the $50 \mathrm{~km}$ wide Canterbury Plains evident to the east. Christchurch is situated at the eastern edge of the Plains, with Banks Peninsula, comprised of tertiary basalt, to the south west of the city.

At Christchurch, the sediments are about $700 \mathrm{~m}$ deep, principally coarse grained fluvial greywacke sands, gravels and silts, but with extensive dune sands in the eastern, seaward part of the city and with intermingled estuarine deposits especially in the central, south and southern-eastern areas. The sediments lie on $200-300 \mathrm{~m}$ of volcanic rock overlying greywacke basement at about $1000 \mathrm{~m}$. To the south of the city, the succession of sediments is broken periodically by buried lava flows (which may have a shielding effect against incoming seismic waves).

The city is an interesting site for a study of seismic hazard with a nearby source of earthquakes, soft sediments likely to amplify ground motions, loose sands likely to liquefy, and the potential for landslides in the several metres of loess that mantle the volcanic hills of Banks Peninsula.

\section{SEISMICITY}

The seismicity model of Elder et al. (1991) has been used with a two modifications: firstly, the activity rate of the Alpine Fault has been increased to allow for the long period of quiescence geologists, the maximum magnitudes in two zones, the Canterbury Plains zone (CPS) and the Banks Peninsula zone (BPS) have been reduced to M6.5 Elder's model itself is a refinement for the central South Island region of an earlier seismicity model by Smith and Berryman (1983), and incorporates smaller source zones than the earlier model, corresponding more closely to the different geologic provinces. It also incorporates recent results from studies of the North Canterbury faults; most notably, trenching on the Hope Fault and several geological studies bringing out the importance of the Porters Pass Fault. (Cowan and McGlone, 1991).

\section{Elder's Model}

The reader is referred to Elder et al.'s report for details of the derivation of the model. In brief, source zones were selected with geologic homogeneity and the distribution of active faults in mind. Known active faults in the region are shown in Figure 4 and the

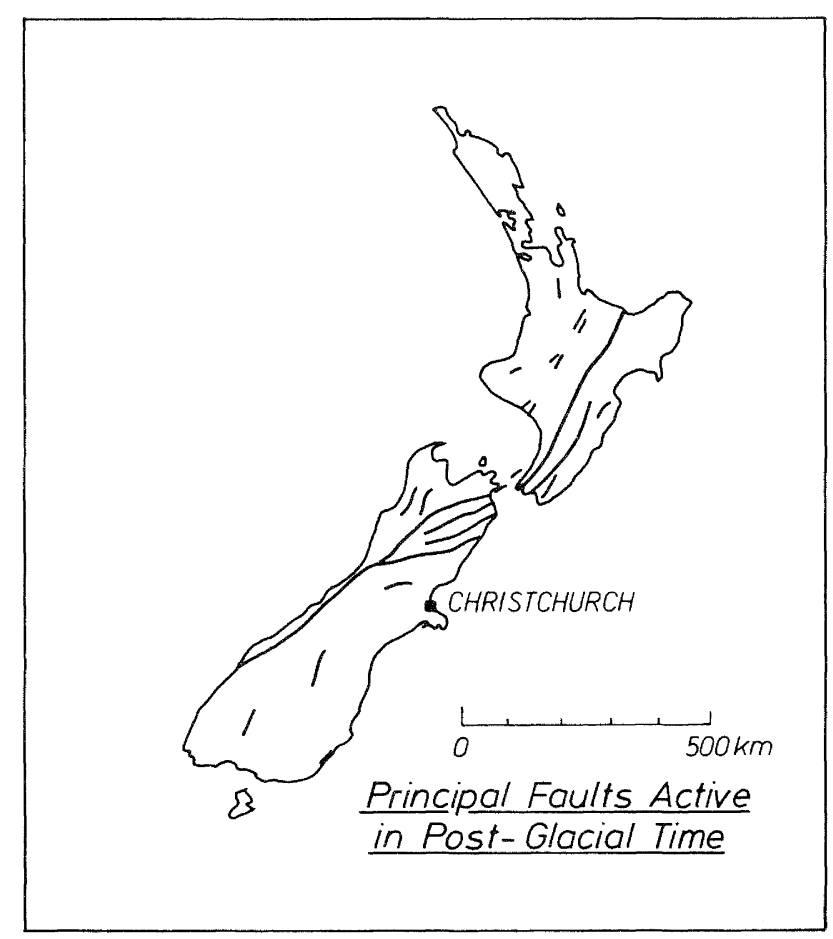

Figure 1. Main active post-glacial faults 
resulting source zones are shown in Figure 5. For each zone, values of the parameters in the truncated Gutenberg and Richter recurrence relation were selected using catalogues of historical earthquakes, and in a few cases of well-studied faults, quaternary offset rates. The maximum (or truncation) magnitude was estimated from maximum fault length in each zone, or again in a few cases, from characteristic offsets and rupture lengths. The parameter values are given in Table 1 .

Note that activity rate is specified by the parameter $a_{4}$, the average annual number of earthquakes with $M>4$ per 1000 $\mathrm{km}^{2}$ rather than the more usual a, the mean annual number of events per unit area with $M>0$. This parameter has been used in previous New Zealand seismicity models, and its use is retained to facilitate comparison between models. Using $\mathrm{a}_{4}$, the Gutenberg and Richter relation becomes

$$
\mathrm{N}(\mathrm{m})=\frac{\mathrm{a}_{4}\left(10^{-\mathrm{b}(\mathrm{m}-4)}-10^{-\mathrm{b}\left(\mathrm{m}_{\operatorname{man}}-4\right)}\right)}{1-10^{-\mathrm{b}\left(\mathrm{m}_{\max }-4\right)}}, \mathrm{m}<\mathrm{m}_{\max }
$$

where $N(m)$ is the mean annual number of earthquakes with $M>m$ per unit area.

\section{Modification to the Alpine Fault Zone}

Heavy rainfall and dense forest on the West Coast of the South Island has discouraged the geological studies of the Alpine Fault that its importance warrants. The only paleoseismic study of the central section, nearest to Christchurch is that of Adams (1980) who used the simultaneous aggradation of rivers crossing the Alpine Fault to infer ruptures of the $300 \mathrm{~km}$ central section at around 550,1000, 1550 and 2200 years bp. These dates together with the lack of recent seismic activity around the Alpine Fault suggest that the fault is leading up to a periodic characteristic rupture, and that the assumption of a uniform temporal (Poisson) distribution of events on the fault is incorrect.

Data from a number of interplate faults around the world suggest that recurrence intervals are lognormally distributed and that, while the mean recurrence interval varies from fault to fault, the coefficient of variation is remarkably stable (Nishenko and Buland, 1987). Evaluating the conditional annual probability of rupture given that the fault has not ruptured during a period about equal to its recurrence interval, results in a probability of rupture two to three times greater than that obtained under the assumption of an exponential (Poisson) distribution of rupture interval. Thus we increased the value of $a_{4}$ for the Alpine Fault by a factor of 2, to allow for this additional information.

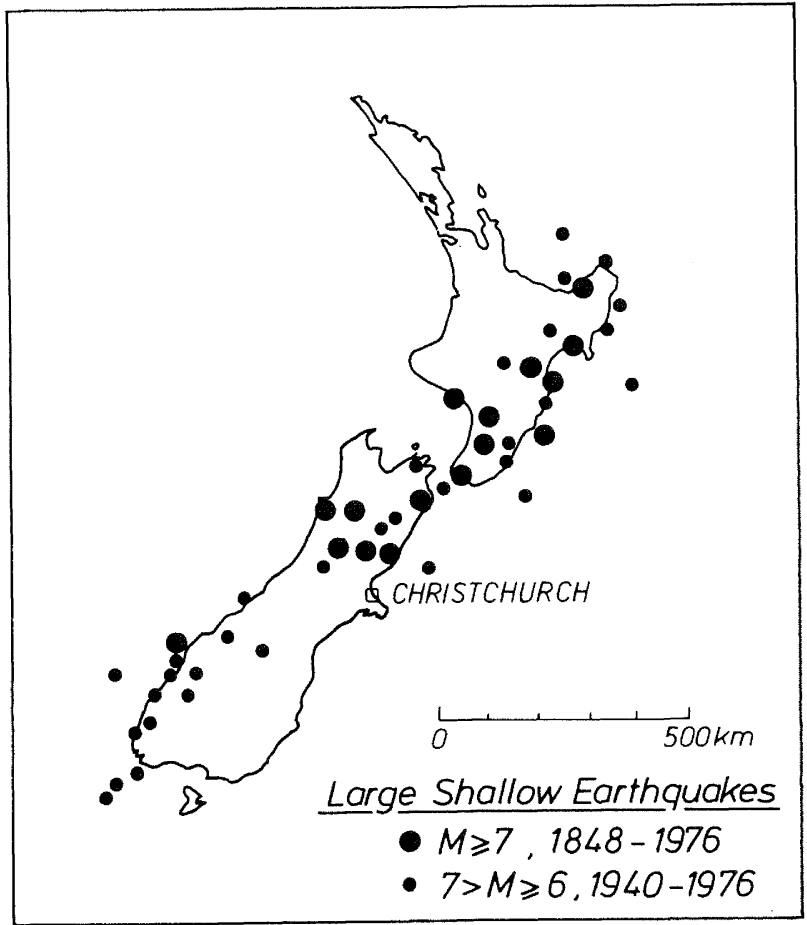

Figure 2. Historical epicentres.

Note gap in central South Island 


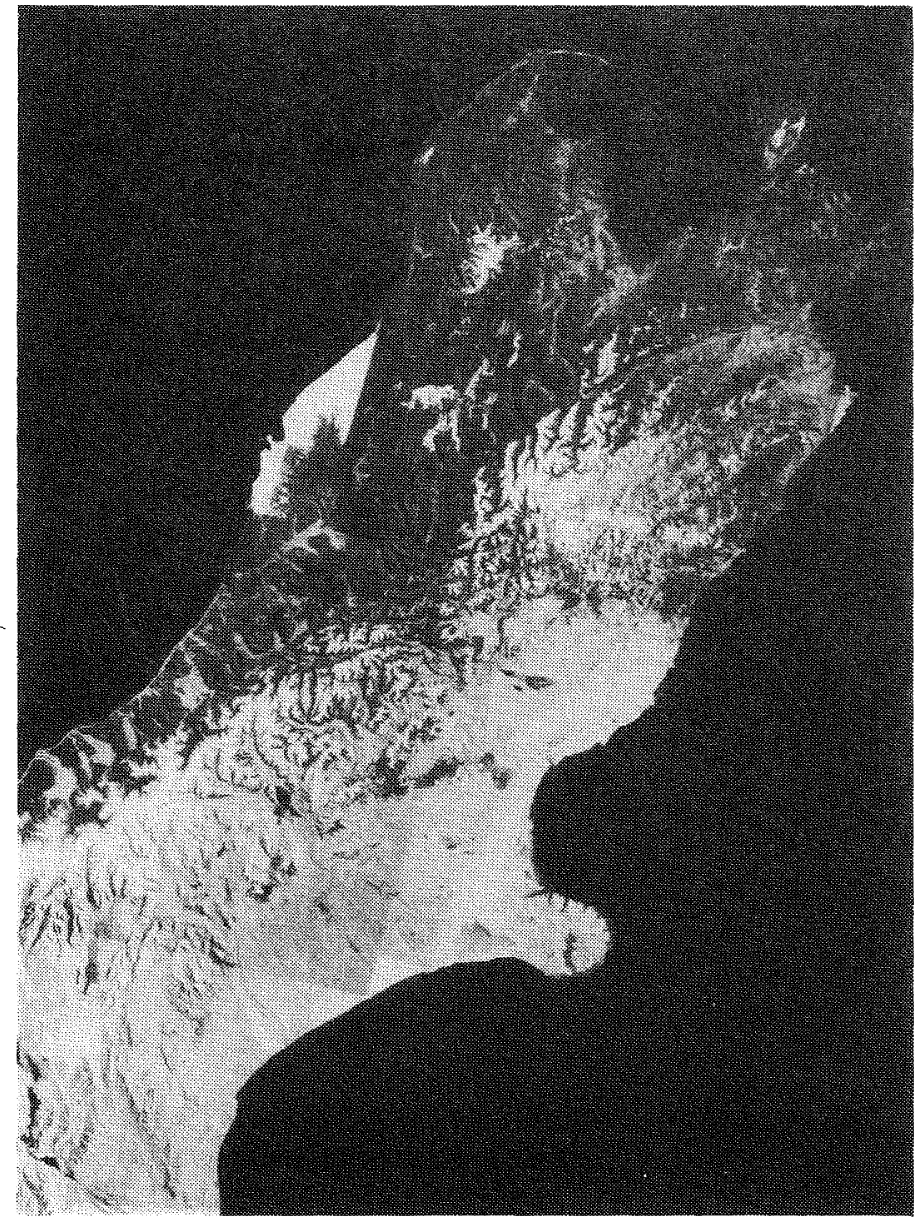

Figure 3. Satellite photograph of central South Island

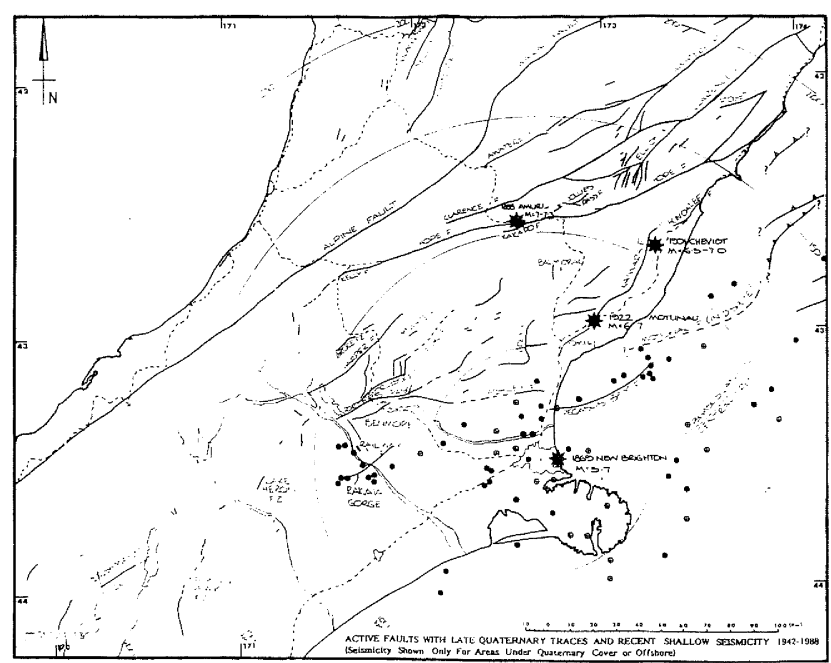

Figure 4. Known active faults in Canterbury Region 


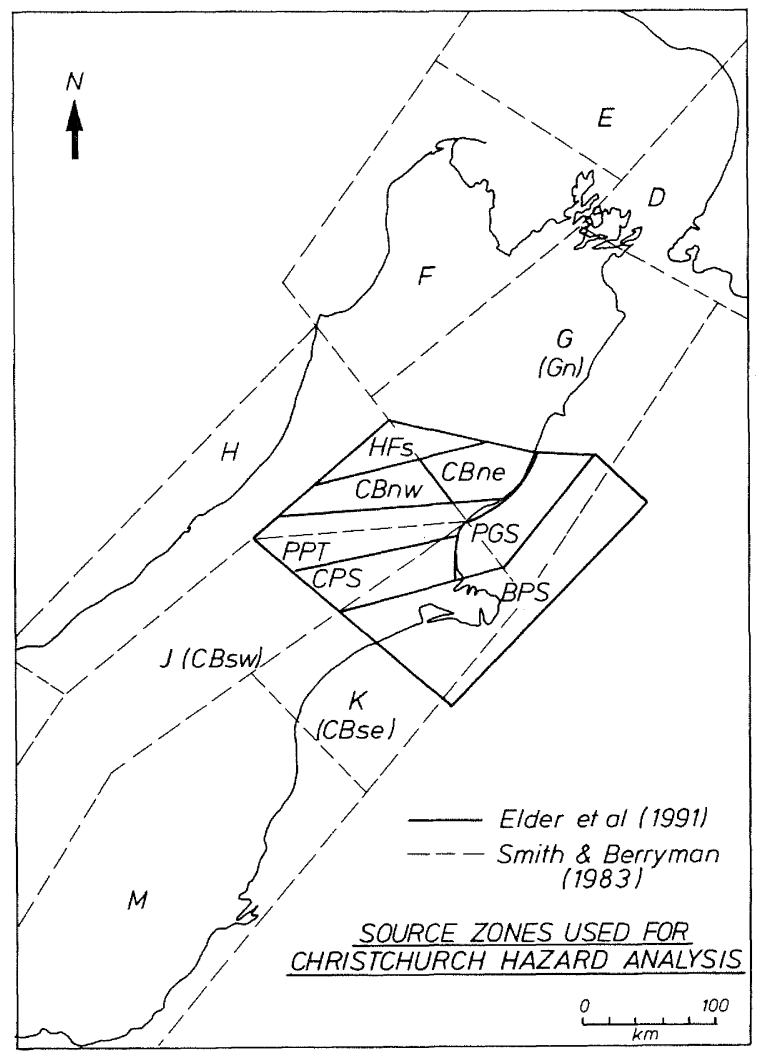

Figure 5. Source zones of Elder et al. 's seismicity model for the central South Island

Table 1 Parameters for seismicity model of Elder et al.. (1991), unmodified.

\begin{tabular}{||l|l|r|rcc||}
\hline Zone & \multicolumn{1}{|c|}{ Description } & $\begin{array}{r}\text { Area } \\
(\mathbf{1 0 0 0} \text { 's } \\
\text { sq km) }\end{array}$ & $\mathbf{m}_{\max }$ & $\mathbf{b}$ & $\mathbf{a}_{\mathbf{4}}$ \\
\hline $\mathrm{Gn}$ & Marlborough & 26.60 & 8.5 & 1.1 & 0.6000 \\
$\mathrm{H}$ & Alpine Fault & 24.37 & 7.0 & 1.05 & 0.1350 \\
& & & & $(\mathrm{M}<6.5)$ & \\
& & & & 0.05 & 0.0025 \\
& & 25.13 & 8.0 & 1.0 & 0.1100 \\
CBsw & SW Canterbury & 9.50 & 8.0 & 1.1 & 0.0300 \\
CBse & SE Canterbury & 3.04 & 7.5 & 0.6 & 0.3000 \\
CBnw & NW Canterbury & 2.60 & 8.0 & 0.5 & 0.1500 \\
CBne & NE Canterbury & 2.50 & 7.8 & 0.5 & 0.1900 \\
HFs & Hope - south/central & 5.08 & 7.5 & 0.8 & 0.3000 \\
PPT & Porters Pass T.Z & 4.07 & 6.5 & 0.8 & 0.0600 \\
CPS & Canterbury Plains & 4.04 & 7.5 & 0.6 & 0.0800 \\
PGS & Pegasus & 13.18 & 6.5 & 0.6 & 0.0150 \\
BPS & Banks Peninsula & & & & \\
F & Smith \& Berryman's: & 31.45 & 8.5 & 1.13 & 0.70 \\
& Zone F & 7.50 & 8.5 & 1.13 & 0.85 \\
D & Zone D & 25.41 & 8.0 & 1.10 & 0.080 \\
M & Zone M &
\end{tabular}




\section{ROCK MOTIONS}

Absolute acceleration response was estimated for a rock site beneath central Christchurch as a function of return period, using the attenuation expression by Kawashima et al. (1984) and the Elder's seismicity model, discussed in the previous section. Of the two attenuation models presented in the TC-4 draft manual, we chose to use the Kawashima et al. model rather than the Joyner \& Boore model for two reasons. Firstly, its simple functional form is easier to work with, both in calculating threshold magnitudes and in making the uncertainty correction; but more importantly, it is derived from data from Japan, which is closer to New Zealand in its tectonics and general geological conditions than is California, the source of much of the data underlying the Joyner \& Boore model.

Uniform risk spectra for a rock outcrop, using Kawashima et al.'s "Hard Soil" parameters (tertiary or older rock or diluvium with $\mathrm{H}<10 \mathrm{~m}$ ) are presented in Figure 6 for various return periods. For computing these spectra, a correction for scatter about the deterministic attenuation expression has been made by multiplying the spectral amplitude

- The reader should note that the expression for $B_{z}$ given by Berrill (1985a) is wrong; in that article, the " +1 " term was omitted from the inner bracket in equation (2) above. estimated for a given return period on the assumption that the attenuation expression is exact by the factor $\sqrt{B_{z}}$, where

$$
\mathrm{B}_{\mathrm{z}}=\exp \left[\frac{1}{2} \frac{\mathrm{b}_{2}}{\mathrm{~b}} \sigma^{2}\left[\frac{\mathrm{b}}{\mathrm{b}_{2}}+1\right]^{2}\right]
$$

in which

$\mathrm{b}=$ the Gutenberg \& Richter "b-value" from the seismicity model

$b_{2}=$ is the coefficient " $b "$ in the Kawashima attenuation expression and

$\sigma=$ standard deviation of natural logarithm of acceleration response data about the attenuation curve.

Derivation of the correction factor $\mathrm{B}_{\mathrm{z}}$ has been presented by a number of authors, eg. McGuire (1974), Peek (1980). The factor $B_{z}$ allows for the inadequacy of a simple attenuation expression to account for the complexities of the generation and propagation of strong ground shaking. This scatter of real data about the mean attenuation curve has its origin in uncertainties in the rupture mechanism, overall propagation path and in local site effects. Since we will make a specific allowance for local site effects in the following section, we arbitrarily chose to apply a correction of $\sqrt{\mathrm{B}}_{\mathrm{z}}$ to account for uncertainties from sources other than site effects.

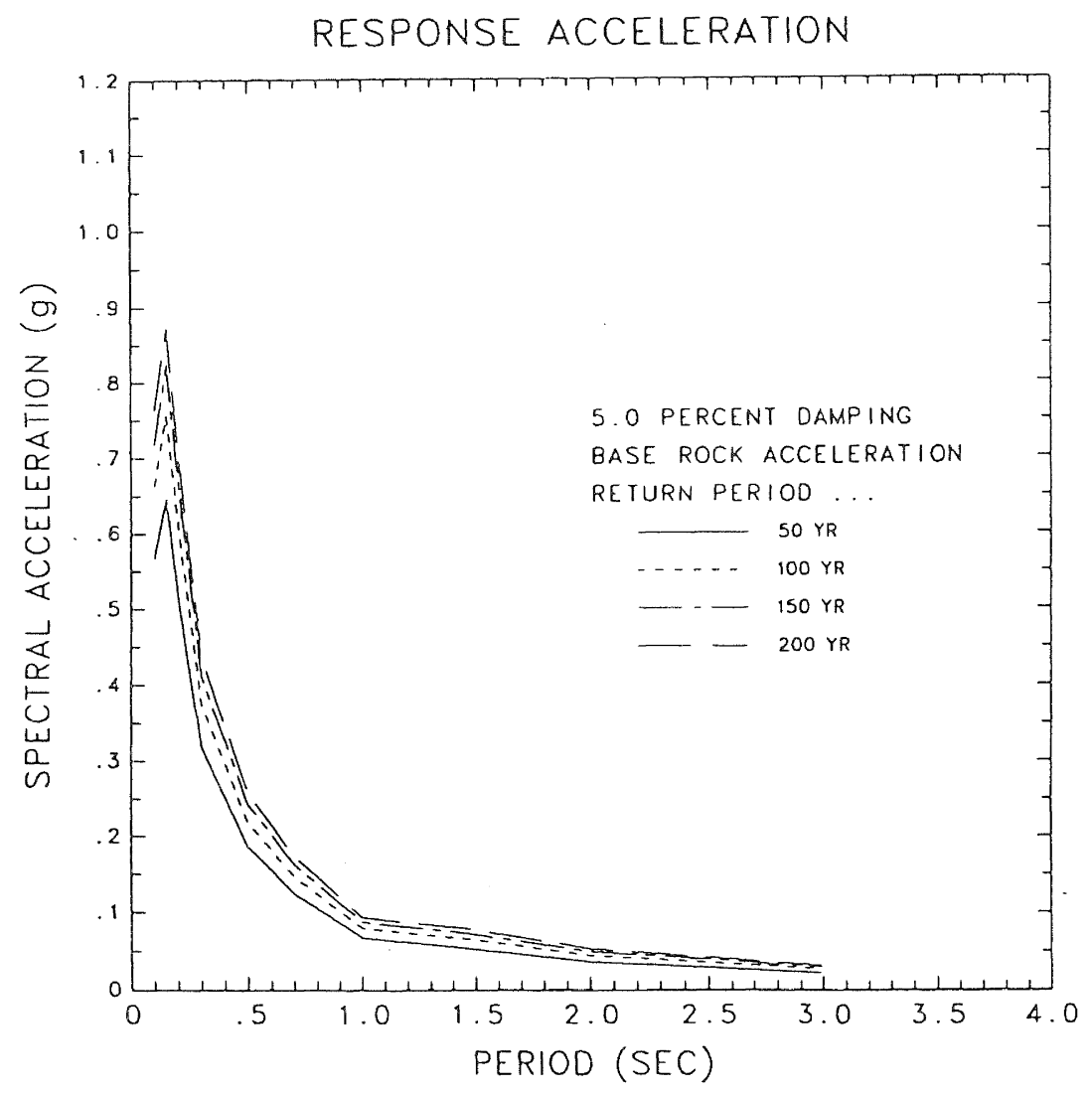

Figure 6. Rock spectra for Central Christchurch Estimated from the EIder seismicity model and Kawashima's attenuation model 
In computing $\mathrm{B}_{\mathrm{z}}$, an average value of the 0.80 was used for the seismicity parameter b. Further discussion of the physical significance of the uncertainty correction can be found in Peek (1980) and Berrill (1985a)."

The non-linear soil model used in estimating transfer functions between rock and stratified soil sites requires an estimate of peak acceleration. For consistency, the attenuation expression for peak acceleration of the same authors (Kawashima et al.,1984, case 7) was used (rather than the more recent expressions given in the draft manual) and values estimated for the same set of return periods.

\section{MODELLING SITE RESPONSE}

Deep deposits of alluvial soils beneath Christchurch are expected to have a significant effect on ground motions experienced during earthquakes. These effects have been modelled in a conventional manner by assuming one-dimensional vertical propagation of SH-waves through the soil column. The acceleration response at any period can be determined by construction of the Thomson-Haskell matrices (Haskell, 1960). These result in a transfer function which gives the ratio of spectral acceleration at the surface to that found at the basement rock.

Non-linear effects are incorporated directly in the frequency domain using the method suggested by Kausel, Roësset, and Christian (1976). Models for shear modulus degradation and damping coefficient published by Sun, Golesorkhi, and Seed (1988) and by Seed, Wong, Idriss, and Tokimatsu (1984) are used to evaluate the effects of strain softening and hysteretic attenuation. The transfer function is calculated iteratively until shear moduli and damping coefficients in each layer are consistent with strain levels found there.

Each of the six sites investigated consists of between 20 and $30 \mathrm{~m}$ of near surface soils, which are different in each case, resting on a uniform sequence of sand and gravel layers extending $675 \mathrm{~m}$ further toward basement rock. These layers rest upon a $300 \mathrm{~m}$ thick layer of weathered volcanics, which in turn rest upon the greywacke basement. The basement rock is assigned a shear wave velocity of $3250 \mathrm{~m} / \mathrm{s}$. The weathered volcanics have an average velocity of $1900 \mathrm{~m} / \mathrm{s}$. The alluvial sediments are assigned progressively smaller shear wave velocities, decreasing from $1700 \mathrm{~m} / \mathrm{s}$ to $400 \mathrm{~m} / \mathrm{s}$ over the $675 \mathrm{~m}$ length of the soil column. Finally, the uppermost 20 to $30 \mathrm{~m}$ consists of layers of sands, gravels, silts, and peats as illustrated in Figure 7.

The basement rock and lower soil profile is based on a single deep bore together with data obtained in seismic surveys as reported by Elder et al. (1991). The upper 20 to $30 \mathrm{~m}$ profiles are all based on carefully logged bore holes at the sites in question.

\section{RESULTS}

Acceleration response spectra for each of the six soil profiles are shown in Figure 8(a) through (f). In each figure, spectra for both 50 year and 150 year return periods are shown.

Significant site effects are found for all six soil profiles. In every case, spectral accelerations are amplified several fold above the corresponding values in the basement rock. Transfer function peaks in the period range $0.5 \mathrm{~s}$ to $1.5 \mathrm{~s}$ have magnitudes in excess of 5.0. Peaks appear consistently at periods near $0.75 \mathrm{~s}$ and $1.1 \mathrm{~s}$, as well as at other periods in the spectrum.
Comparing the 50 and 150 year return period results, it can be seen that at longer periods the 50 year spectra are considerably lower than those for 150 years. At periods shorter than about $0.3 \mathrm{~s}$ however, the 50 year spectra are often equal to or even slightly higher than the corresponding 150 year values. This reversal is due to the strain controlled damping increase and shear modulus decrease which is incorporated in the site response calculation. The stronger motions associated with the longer return period lead to larger strains and hence more hysteretic damping, and the increased damping has an enhanced effect at shorter periods where more stress reversals occur in each wave passage.

Comparison of the six separate site spectra shows a natural division into two groupings. Sites $\mathrm{A}, \mathrm{C}$, and $\mathrm{E}$ all exhibit relatively softer response when compared to sites $\mathrm{B}, \mathrm{D}$, and $\mathrm{F}$. This is illustrated quite clearly in Figure 9(a) and (b) where the two groupings are plotted together for the 150 year return period.

On Figure 9(a), it can be seen that site A has response very similar to site E with the exception of a spike at $0.2 \mathrm{~s}$. This spike is a direct consequence of the softer silt layers found near the surface at Site A. As can be seen from Figure 7, site C is significantly softer than any of the other five sites, and this is reflected in the more pronounced amplification at periods in excess of about $0.8 \mathrm{~s}$. If we neglect the $0.2 \mathrm{~s}$ spike for site A, all three of these sites exhibit a relatively flat spectrum with a response acceleration of roughly $0.7 \mathrm{~g}$ extending to a period of roughly $1.0 \mathrm{~s}$

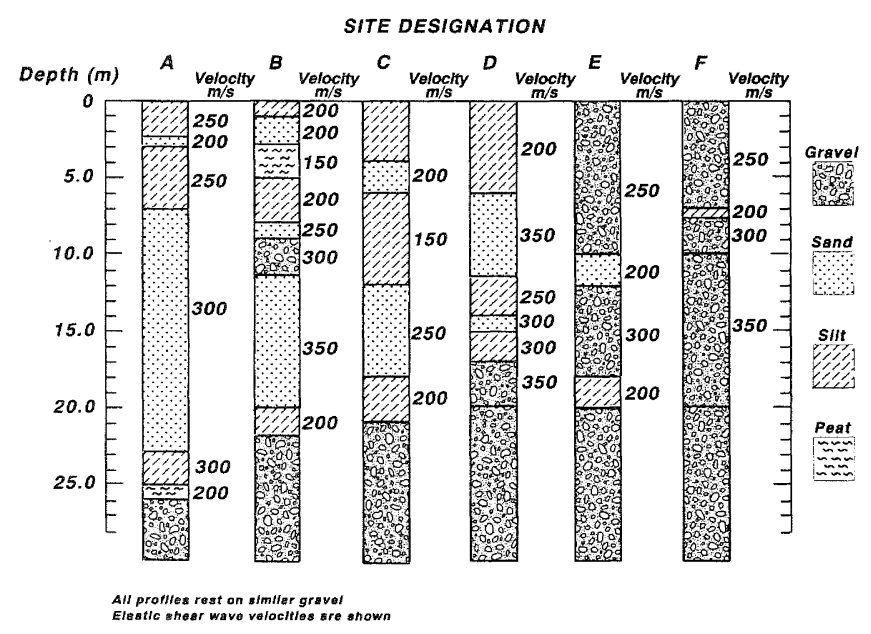

Figure 7. Shows the upper $30 \mathrm{~m}$ of the soil profiles at the 6 test sites. These strata are underlain by a sequence of sand and gravel layers $675 \mathrm{~m}$ thick, resting in turn on a $300 \mathrm{~m}$ thick layer of weathered volcanics overlying greywacke basement.

In contrast to sites $\mathrm{A}, \mathrm{C}$, and $\mathrm{E}$, sites $\mathrm{B}, \mathrm{D}$, and $\mathrm{F}$ all exhibit stronger response at shorter periods as can be seen from Figure 9(b). Spectral ordinates in excess of $1.0 \mathrm{~g}$ occur at periods of less than about $0.4 \mathrm{~s}$. Of these three sites, D and $\mathrm{F}$ have very similar response, while the response for site B is suppressed at very short periods. 
RESPONSE ACCELERATION
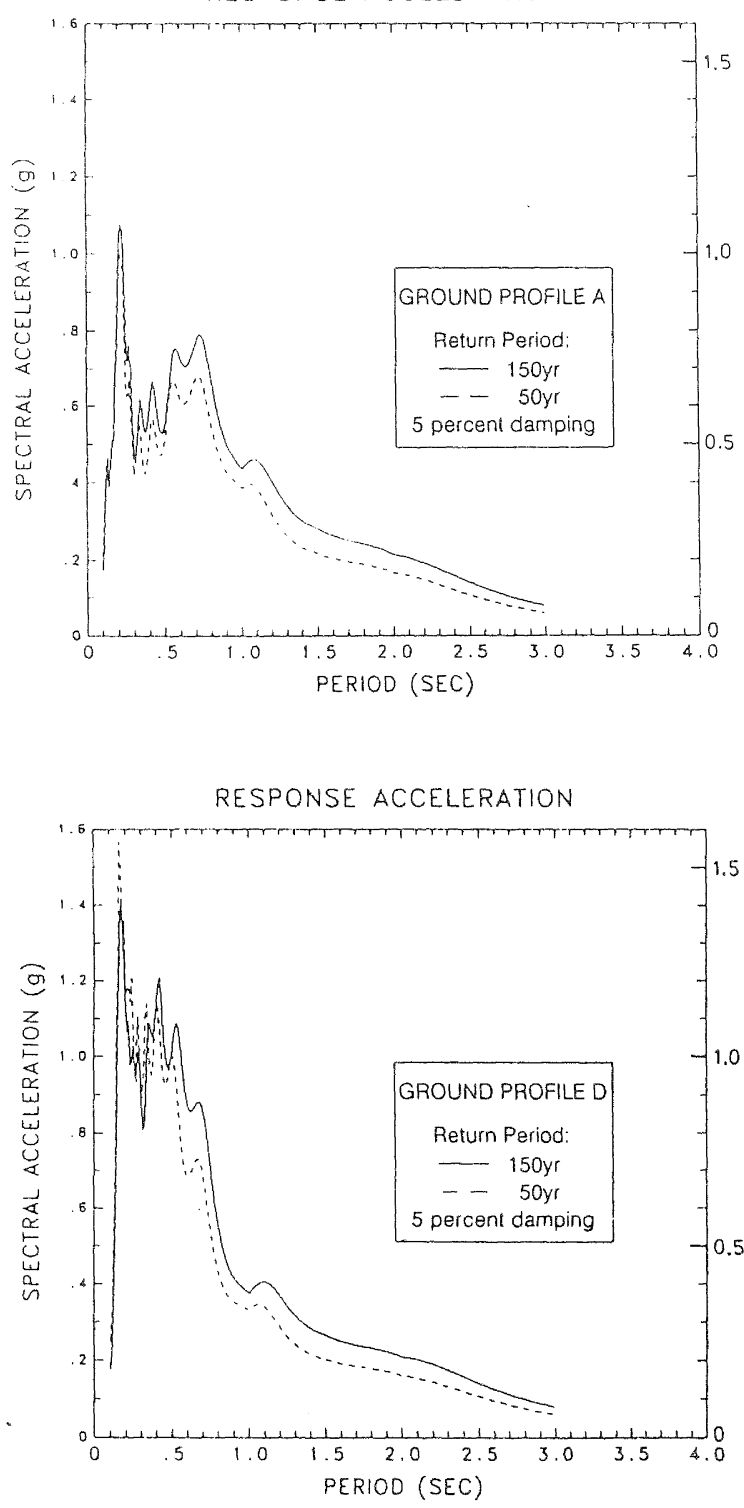

RESPONSE ACCELERATION

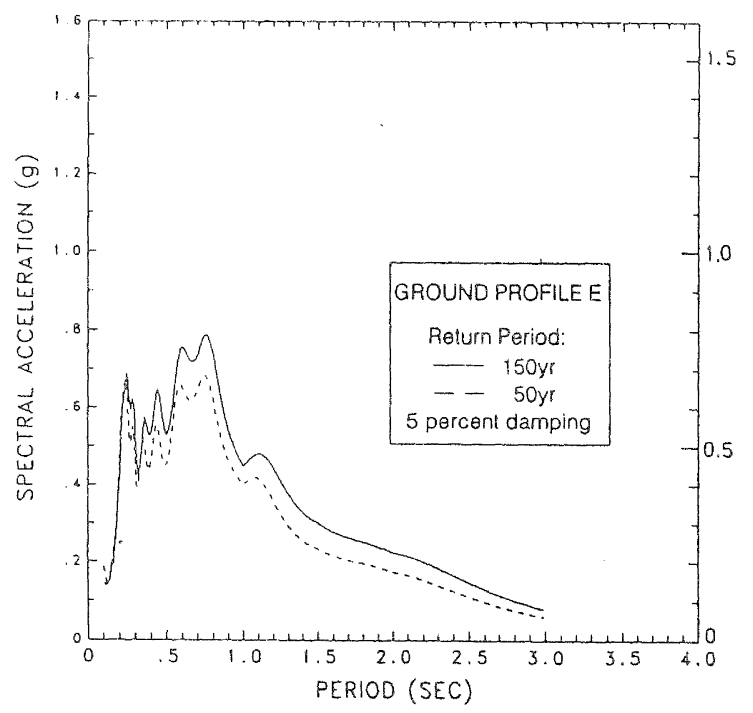

RESPONSE ACCELERATION

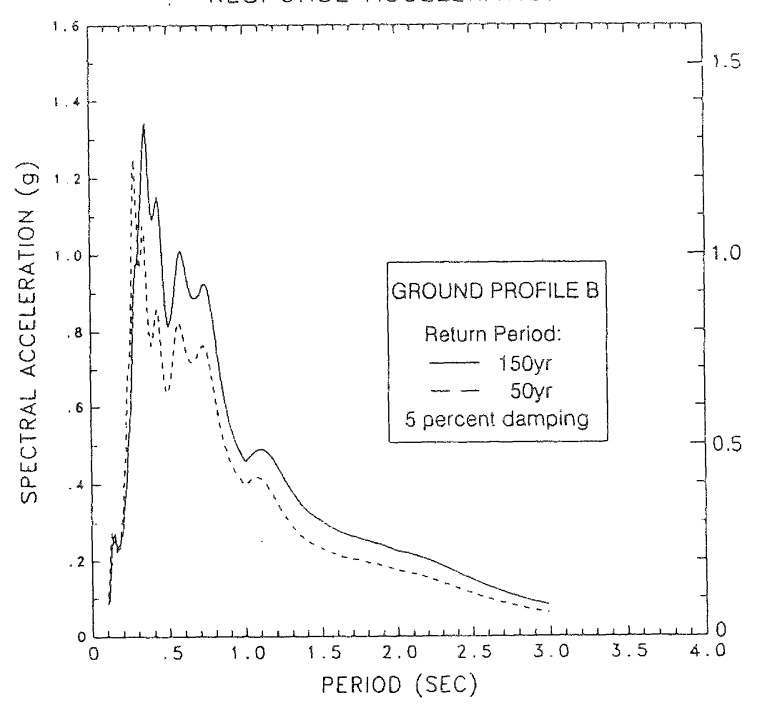

21
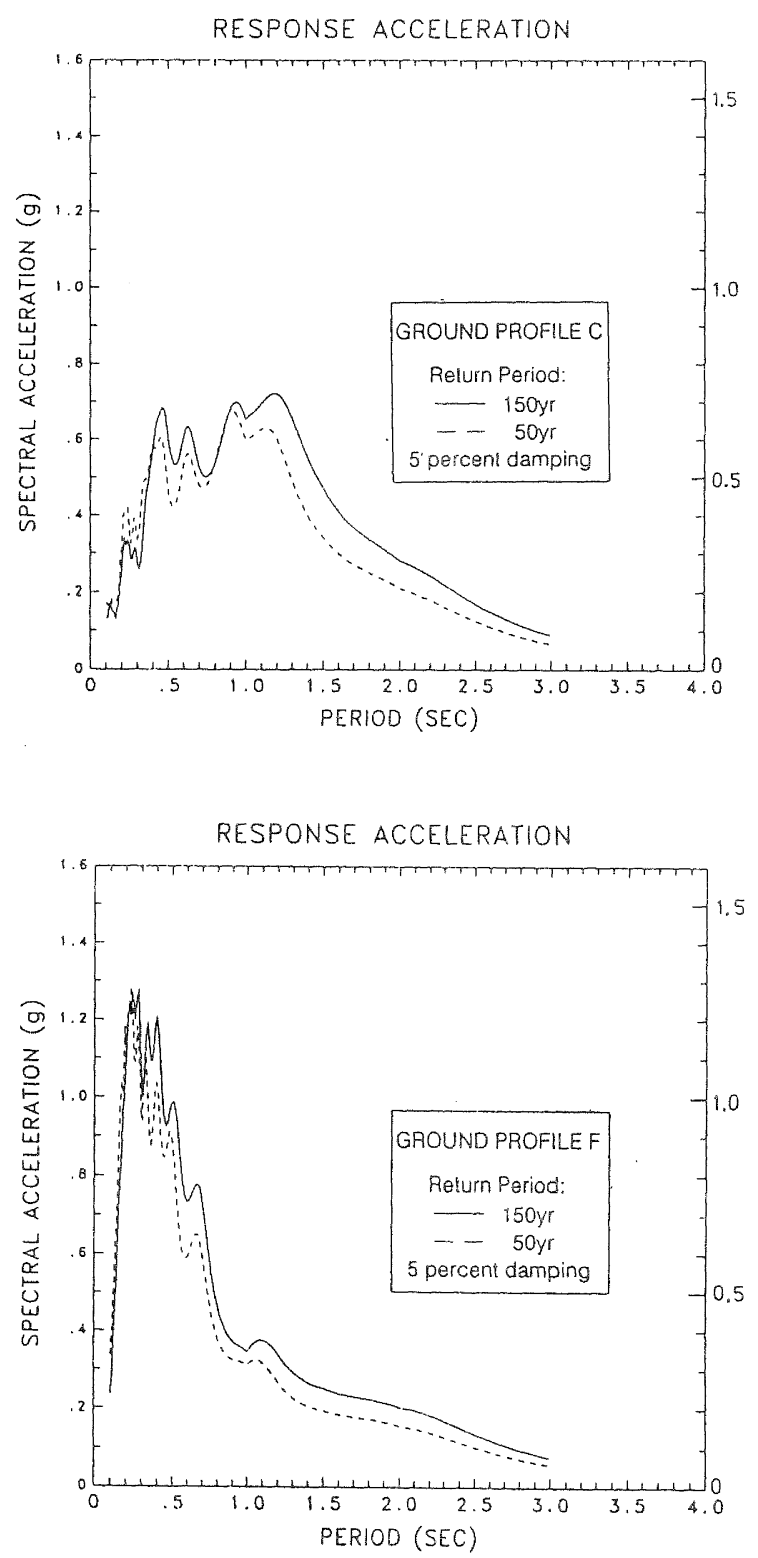

Figure 8. Uniform risk acceleration response spectra for the six sites, after modification by the site transfer functions. 
The differences between the various site responses can be traced to certain characteristics of the six soil profiles. First note that at all three of the softer sites, A, C, and E, there exists a soft layer or layers at a depth near $20 \mathrm{~m}$. It is this layer which suppresses the short period amplification and produces the relatively flat spectrum for periods below about $1.0 \mathrm{~s}$. In the case of site $C$, the soils above the silt layer at $20 \mathrm{~m}$ depth are significantly softer than those at sites A and E, and these lead to greater amplification at periods between $1.0 \mathrm{~s}$ and $1.5 \mathrm{~s}$.

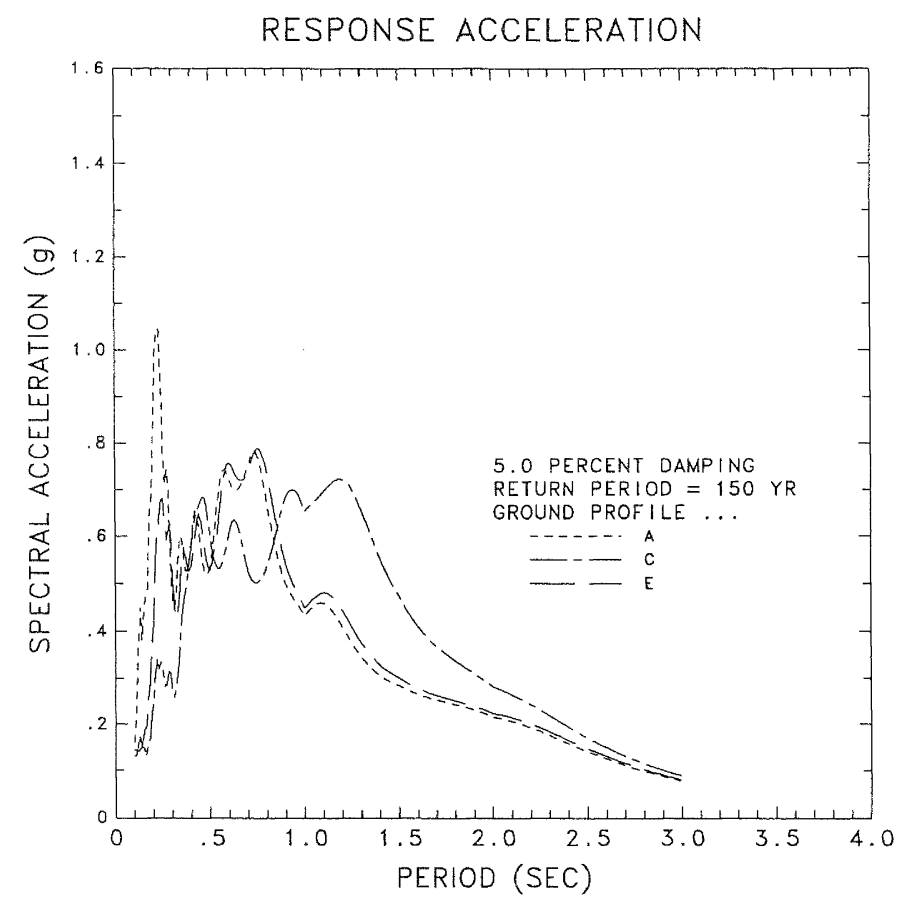

(a)

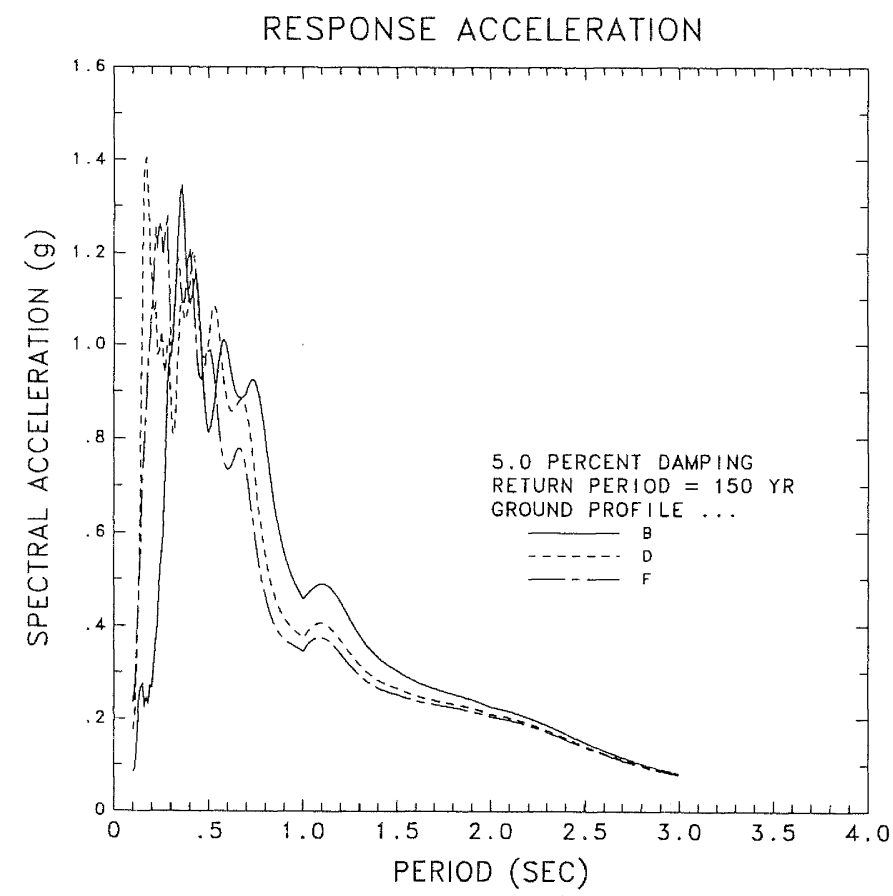

(b)

Figure 9. Site-specific spectra grouped according to site stiffnesses 
For sites $\mathrm{D}$ and $\mathrm{F}$ no corresponding soft layer is found at the $20 \mathrm{~m}$ depth. In the case of site $\mathrm{F}$, stiff gravels dominate the site response, and, while site $D$ does possess silts, these are both stiffer and too near the surface to attenuate the short return period response. Site B at first appears to possess the characteristics of the softer sites, exhibiting a soft silt layer at $21 \mathrm{~m}$ depth. However, this layer does not dominate the response as in the cases of sites $\mathrm{A}, \mathrm{C}$, and $\mathrm{E}$. The upper layers at site $\mathrm{B}$, especially the peat layer at $4 \mathrm{~m}$ depth, bring about amplification at periods between $0.3 \mathrm{~s}$ and $0.7 \mathrm{~s}$ which result in the apparently stiffer response seen at this site.

In attempting to interpret the results given here, we have performed other calculations based on simulated profiles. Certain broad conclusions can be drawn. All these simulated profiles rest on the common gravel/volcanics/greywacke basement used for the six site response studies. We then experimented with the location of the soft silt layer found at site $\mathrm{E}$. If this layer is moved closer to the surface, its effect in suppressing short period response is diminished. If it is moved up to a depth of $10 \mathrm{~m}$, the response is much more like that found for site $F$. For depths between $10 \mathrm{~m}$ and $20 \mathrm{~m}$, greater and greater attenuation of short period response is observed. Evidently, the existence of a soft layer is not sufficient to result in the characteristic soft site response found at sites A, C, and E. The depth of the layer is also of particular importance.

In the case of site $B$, where the soft layer at $20 \mathrm{~m}$ depth is found, we have experimented by removing the upper soft layers, especially the peat layer. If the peat and silt layers above $10 \mathrm{~m}$ depth are replaced by sands with $200 \mathrm{~m} / \mathrm{s}$ shear wave velocity, the response becomes very similar to that found for site $\mathrm{E}$. Similarly, if the surface silts found at site A are replaced by sands, the response spike at $0.2 \mathrm{~s}$ disappears. Evidently, the presence of soft soils quite near the surface can produce short period amplifications which may dominate the response.

To summarize, the six soil profiles investigated here fall into two response categories: soft response, characterized by a flatter spectrum with lower, broader spectral acceleration; and stiff response, characterized by a more peaked spectrum with greater accelerations at short periods. The presence or absence of soft layers within the soil profile has a marked effect on site response. Soft sites are all characterized by a soft layer near $20 \mathrm{~m}$ depth. However, the presence of a soft layer at $20 \mathrm{~m}$ is not sufficient to ensure soft response. Other soft layers nearer the surface may significantly alter the short period response.

\section{ZONATION AND DESIGN SPECTRA}

Figure 10 shows the location of the five inner city sites and the outlying site at Christchurch Airport, $8 \mathrm{~km}$ northwest of the city centre. Given the large amount of variation between the profiles and the marked differences in response, it is clear that more closely spaced soil profiles are required for the construction of a zoning map, even for the inner city where the profiles are about $1 \mathrm{~km}$ apart. The draft manual recommends working to a $0.5 \mathrm{~km}$ grid, and that seems reasonable and indeed necessary for our test case of Christchurch.

To carry the pilot study through to conclusion we have fitted smooth curves to the two categories of response spectra. The results are shown in Figure 11. For the three sites in the stiff response category, a constant acceleration response of $1.2 \mathrm{~g}$ is adopted for natural periods $\mathrm{T}$ less than $0.4 \mathrm{~s}$, with constant velocity response for the band $0.4<\mathrm{T}<2.5$. $\mathrm{s}$, and constant displacement response for $\mathrm{T}>2.5 \mathrm{~s}$. This curve is shown in Figure 11(b). Note that occasional isolated peaks such as that for profile $\mathrm{D}$ at $\mathrm{T}=0.15 \mathrm{~s}$ are allowed to rise above the "design" curve. It is believed that period lengthening would move response away from the peak, should a structure have an undamped natural frequency corresponding with an isolated spectral peak.

For sites in the soft response category, we have employed the same "design" curve except that the constant acceleration response section extends to $T=0.7 \mathrm{~s}$ and has a value of $0.7 \mathrm{~g}$ rather than $1.2 \mathrm{~g}$. For the special case of site $\mathrm{D}$, the constant acceleration segment is carried further to $T=1.15 \mathrm{~s}$ and the constant displacement response $\left(S_{a}=1.2 / T^{2}\right)$ line is extended back to a period of $1.5 \mathrm{~s}$, with a short, constant-velocity segment joining the two.

In both categories, the "design" envelopes are about $40 \%$ higher than the computed site spectra at the longest period considered, $\mathrm{T}=3.0 \mathrm{~s}$. We feel that it is prudent to retain this margin because of the likelihood of a great earthquake on the Alpine Fault within the next 100 years or so, and the consensus amongst seismologists that such an earthquake would generate strong long-period motions.

\section{COMPARISON WITH OTHER ZONATIONS}

Two comparisons can be made between the results of this pilot study and independent estimates of seismic hazard for the city. The first comparison is with the New Zealand "Loadings Code", NZS 4203 which is applicable to buildings and some other structures. This code is in the process of being revised and we have used the spectra from the draft revised version in the comparison below. The commentary to the draft code explains that the specified seismic loadings are based on an average return period of 500 years, but are then reduced by 50 percent, corresponding to a structural performance factor of 2 . Using typical values of $b$ and $\hat{b}$ from the seismicity and attenuation models, a 500 years spectrum reduced by 50 percent corresponds roughly to the spectrum for a 125 year return period. Thus the draft code spectrum is comparable in terms of return period to our 150 year spectra.

The code has three categories of ground condition corresponding roughly, through not exactly, with the three ground groups of Kawashima et al. (1984). Because of the great depth of alluvium beneath the city, Christchurch is clearly in the softest soil category. The 5 percent-damped elastic response spectrum of the proposed revisions of the code, for "flexible or deep soil sites", is plotted in Figure 12 against our spectra for the three soft soils. For periods less than about 1.5 seconds, it plots about 30 to 40 percent below the estimates of this study. For our "stiff" sites, which according to the code rules would be in the flexible or deep soil site category also, the difference would be very much greater at very short periods. At first sight, it might seem that the differences are due to the specific allowance for site effects in this pilot study, but that is not necessarily the case as the second comparison shows. 


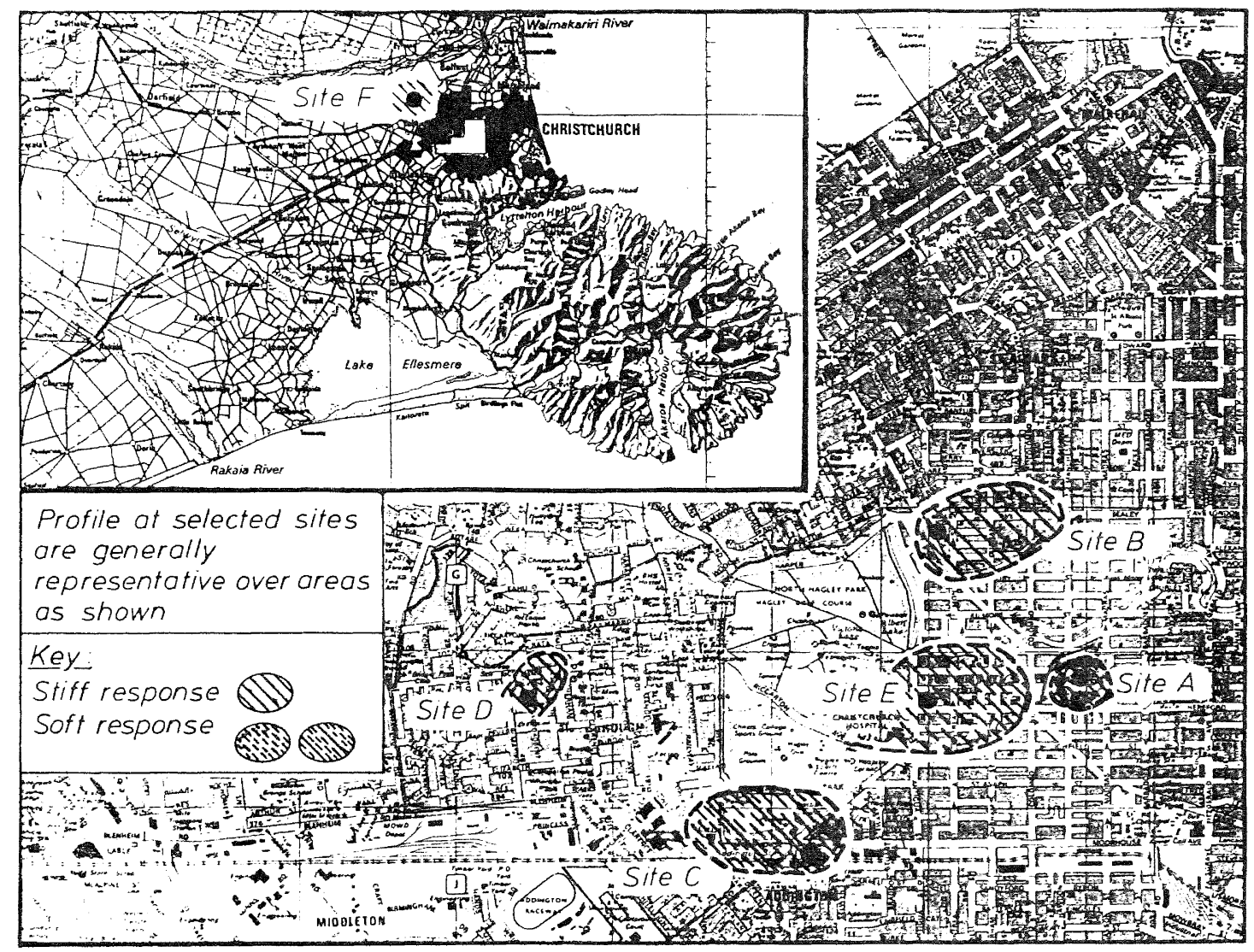

Figure 10. Location of sites

In the second comparison, we do not make a specific allowance for site effects, but simply employ Kawashima's soft-soil attenuation expression and compute uniform risk spectra directly for Christchurch, using the same seismicity model. This is the procedure also followed by the code committee albeit with a different, less detailed, seismicity model and with a different, earlier Japanese attenuation model (Matuschka et al. 1985). This comparison employs the grade 1 technique of the manual. The resulting spectrum in this case plots just above the softer site-specific spectra, and suggests that the site-effects computations of this pilot study are not grossly in error.

\section{CONCLUSIONS}

The Grade 3 procedures of the draft manual have been followed in this pilot study to estimate ground shaking at six distinct sites in the city of Christchurch. The procedures set out in the manual were easy to follow, strike a good balance between providing a clear background and giving too much detail; we find it difficult to fault them.
The resulting uniform risk spectra have generally the same shape as those being used or being advocated independently for use in Christchurch, but the difference in amplitudes between the spectra of the pilot study and those of the draft N.Z. Loadings Code cause us concern. Since the methods of the TC4 manual are more refined than those of the draft code, and a more detailed seismicity model is employed in the pilot study, we are worried that the proposed code underestimates hazard in Christchurch.

In our computations, we made two additions to the procedures of the draft manual which we feel might be considered for adoption in the final document. The first covers the case of a fault known to generate a characteristic earthquake and where there is information about the mean recurrence interval and the time elapsed since the last rupture. Nishenko and Buland (1987) describe how the conditional probability of rupture during any arbitrary future period may be calculated, and Rhodes and Millar (1983) suggest that the real hazard posed by such a fault may be estimated by using the customary Poisson temporal distribution but with a factor applied to the activity rate (Gutenberg and Richter's a-value). This factor is a function of the ratio of time elapsed since last rupture to average rupture interval, and of the standard deviation of the log of inter-rupture time. 


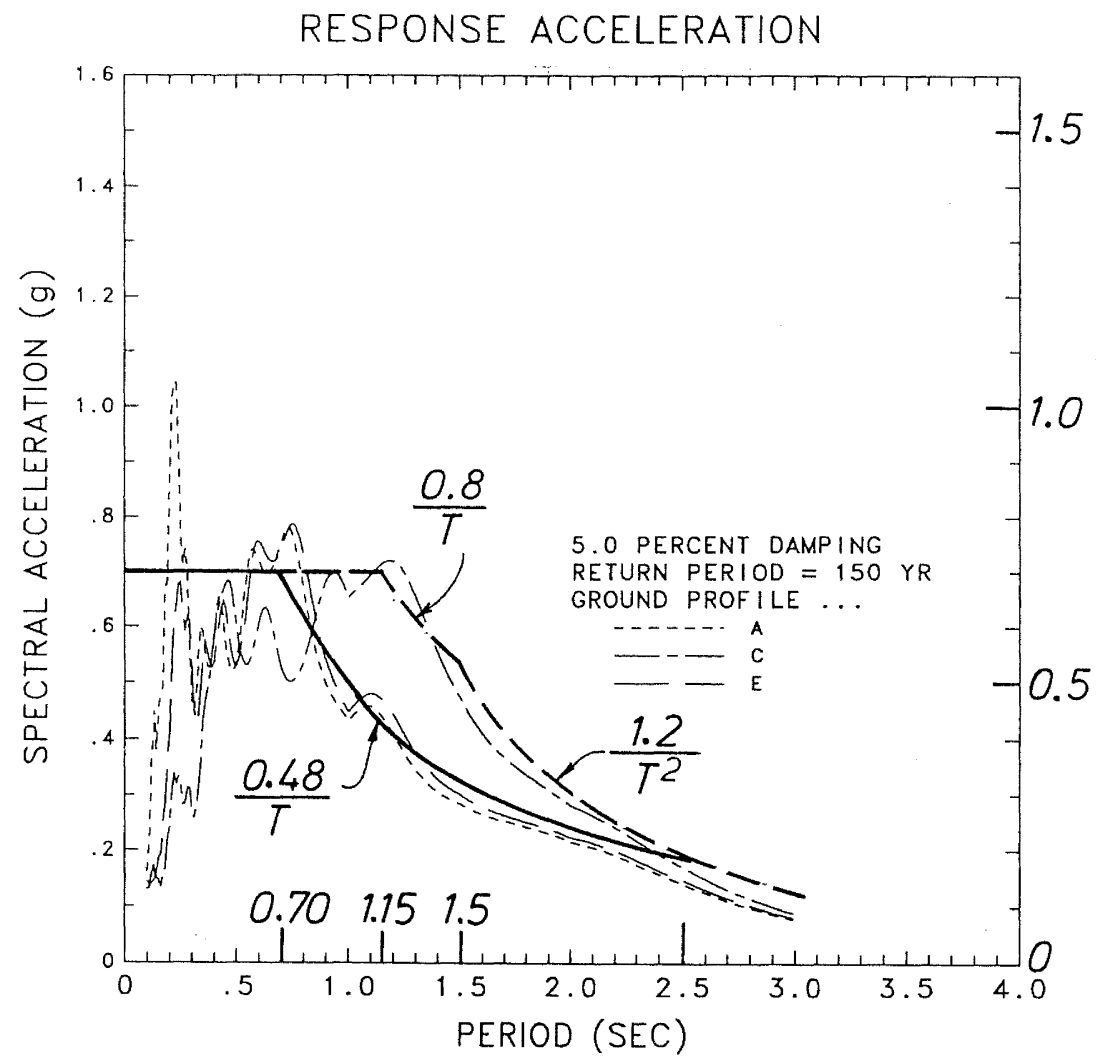

(a)

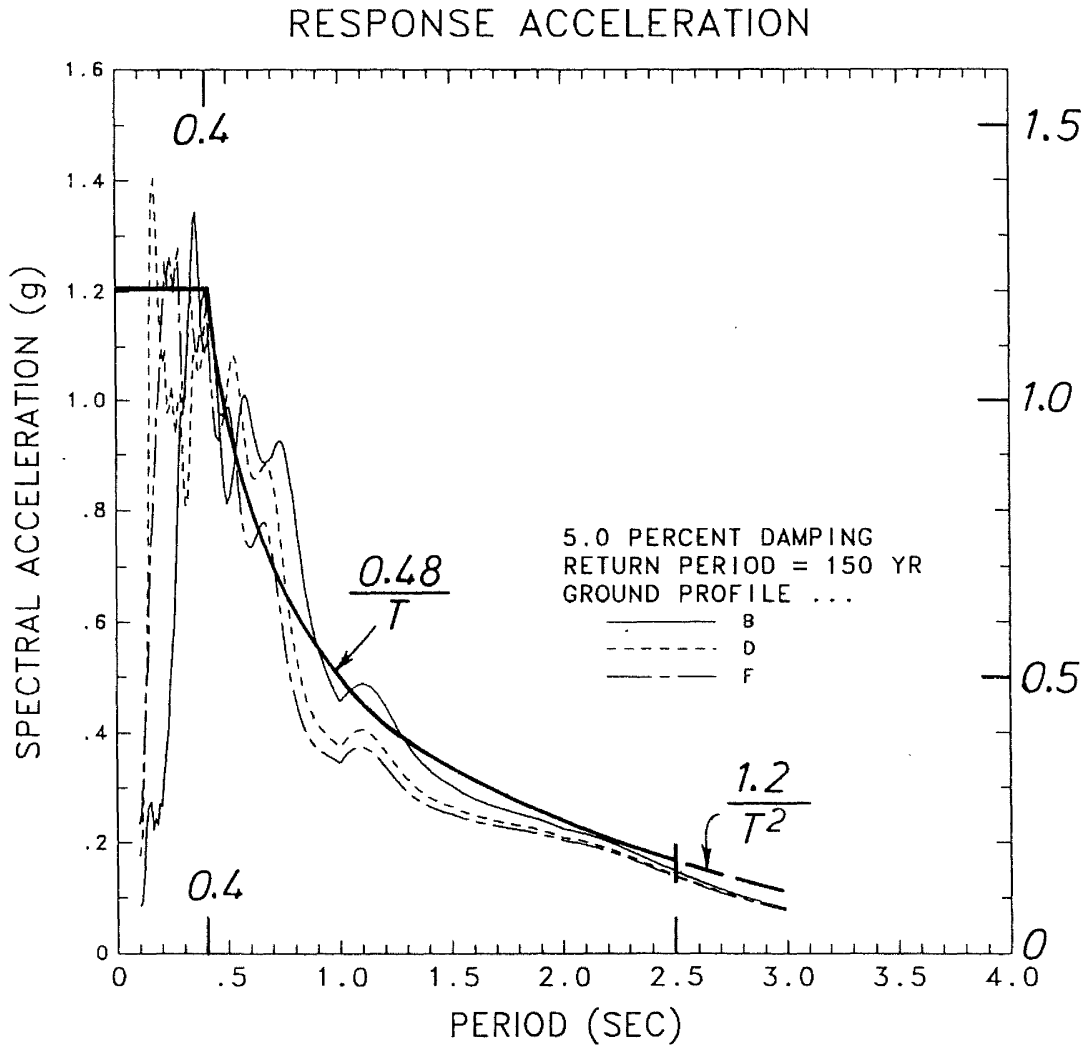

(b)

Figure 11. "Design" spectra for soft (a) and stiff (b) sites 
The second step we added to the hazard computation was to allow for scatter about the mean attenuation curve. Observations suggest that actual ground motion intensities are lognormally distributed about mean attenuation curves (McGuire, 1974; Katayama et al., 1978; Berrill, 1985b). Assuming that the scatter is independent of distance and magnitude results in independent correction factors which should be applied to the rate of occurrence corresponding to a given intensity (the " $A_{z}$ factor") or to the intensity of shaking estimated for a given return period where the factor $B_{z}$ is used. For attenuation models of the form used by Kawashima et al., the corrections can be estimated in closed form and the factor $B_{z}$ is given by Eq. (2).
Finally, we must remark upon the sensitivity of the site response model to small variations in input parameters. In order to calibrate site response models and to give experience in judging parameter values it would be helpful to have easy reference to a set of case histories. In estimating shear wave velocities, the article by Fumal and Tinsley (1985) was helpful and it might be usefully added to the references of the draft manual.

\section{ACKNOWLEDGEMENTS}

The authors wish to acknowledge the support and encouragement in this work of the NZ Earthquake and War Damage Commission and a number of Christchurch Consulting Engineering companies; in particular, the Holmes Group, Powell Fenwick and Partners and Soils and Foundations Ltd. They also wish to thank Drs J R Pettinga and H Cowan for many helpful discussions about fault activity in the region.

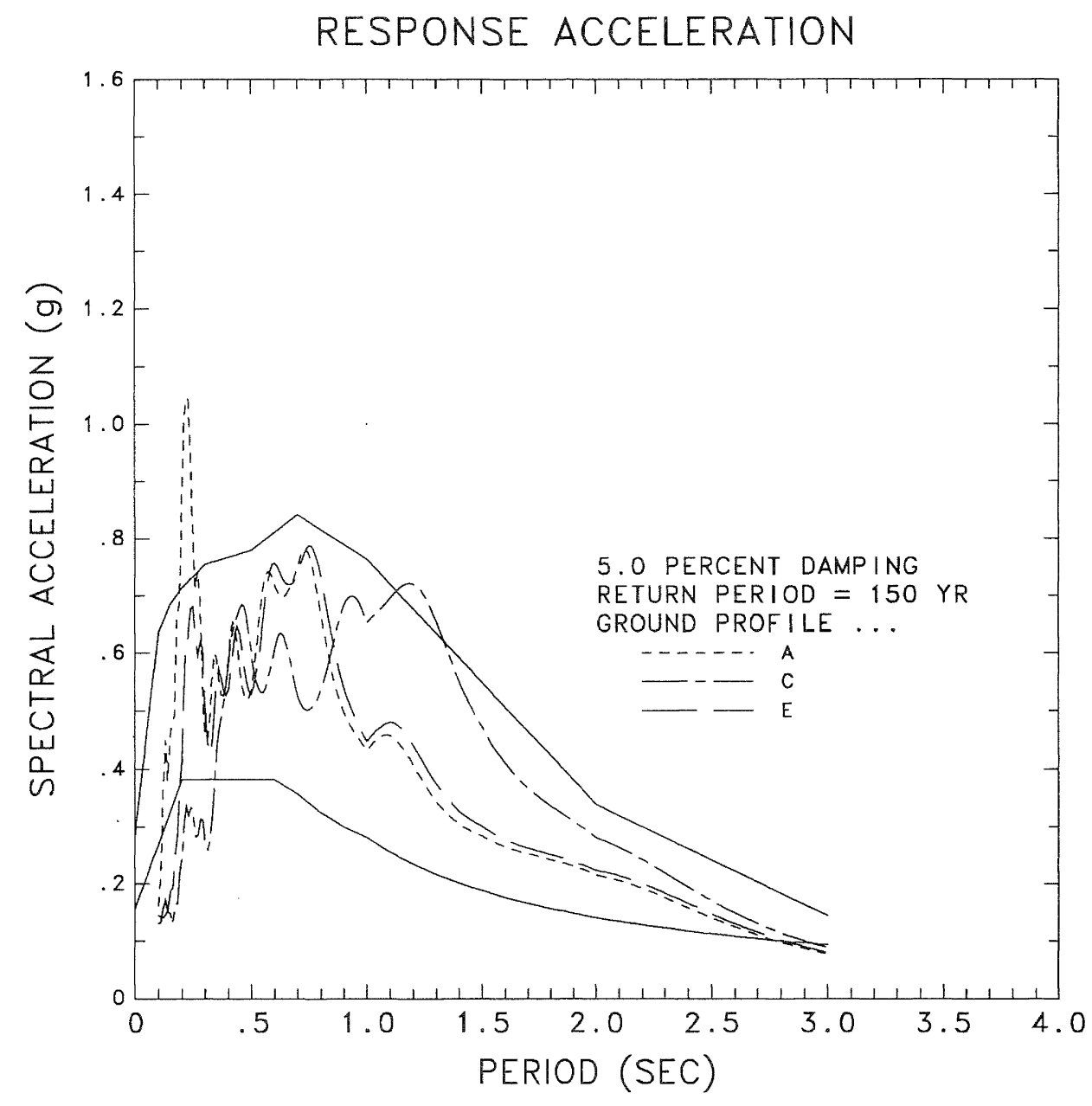

Figure 12. Comparison of response spectra for the three sites exhibiting soft behaviour with the proposed revisions to the $\mathrm{NZ}$ Loadings Code, NZS 4203, and the corresponding uniform risk spectrum derived by Class 1 methods, using the ground group 3 attenuation parameters and the same seismicity model. 


\section{REFERENCES}

Adams, J. (1980) "Paleoseismicity of the Alpine Fault Seismic Gap, New Zealand" Geology, Vol. 8, pp 72-76.

Berrill, J.B. (1985a) "Seismic Hazard Analysis and Design Loads", Bull. N.Z. Nat. Soc. Earthq. Eng., Vol. 18, No 2, pp. 139-150.

Berrill, J.B. (1985b) "Distribution of Scatter in New Zealand Accelerograph Data", Bull. N.Z. Nat. Soc. Earthq. Eng., Vol. 18, No. 2, pp. 151-164.

Cowan, H.A. and McGlone, M. (1991) "Large Prehistoric Earthquakes and Rate of Slip on the Hope Fault at Glynn Wye, North Canterbury". J. Roy. Soc. N.Z., Vol. 21, pp 373-384.

Cornell, C.A. (1968) "Engineering Seismic Risk Analysis", Bull. Seism. Soc. Am., Vol. 58, pp 1583-1601.

Elder, D.McG., McCahon, I.F. and Yetton, M.D. (1991) "The Earthquake Hazard in Christchurch: a Detailed Evaluation", Research Report to EQC, Soils and Foundations Ltd, Christchurch, N.Z., 131 pp.

Fumal, T.E. and J.C. Tinsley (1985) "Mapping Shear-Wave Velocities of Near-Surface Geologic Materials", USGS Professional Paper No. 1360, pp. 127-149.

Haskell, N.A. (1960) "Crustal Reflection of Plane S-H Waves", Jour. Geophys. Res., Vol. 65, pp. 4147-4150.

Joyner, W.B. and Boore, D.M. (1982) "Prediction of Earthquake Response Spectra", US Geol. Surv. Open-File Rept. 82-977, 16pp.

Katayama, T., Iwasaki, T. and Seaki, M., (1978) "Statistical Analysis of Earthquake Acceleration Response Spectra", Trans. Japanese Society Civ. Eng., Vol. 10, pp. 311-313.

Kausel, E., Roësset, J.M., and Christian, J.T. (1976) "Nonlinear Behavior in Soil-Structure Interaction", Jour. Geotech. Div. ASCE, Vol. 102, GT11, pp. 1159-1170.

Kawashima, K., Aizawa, K. and Takahashi, K. (1984) "Attenuation of Peak Ground Motion and Absolute Acceleration Response Spectra", Proc. 8th World Conf. Earthq. Eng., San Francisco, Vol. II pp 257-264.

McGuire, R.K. (1974) "Seismic Structural Response Risk Analysis Incorporating Peak Response Regressions on Earthquake Magnitude and Distance", $\mathrm{PhD}$ thesis, Mass. Inst. of Technology, $371 \mathrm{pp}$.

Matuschka, T., Berryman, K.R., O'Leary, A.J. McVerry, G.H. Mulholland, W.M. and Skinner, R.I. (1985) "New Zealand Seismic Analysis", Bull. N.Z. Soc. Earthq. Eng., Vol. 18, No. 4 , pp. 313-322.

Nishenko, S.P. and Buland R. (1987). "A Generic Recurrence Interval Distribution for Earthquake Forecasting", Bull. Seism. Soc. Am., Vol. 77, pp. 1382-1399.
Peek, R.L. "Estimation of Seismic Risk for New Zealand : A Seismicity Model and Preliminary Design Spectra", Research Report No. 80-211, Dept. of Civil Engineering, University of Canterbury, $84 \mathrm{pp}$.

Rhodes, D.A., and Millar R.B. (1983) "Estimating the Hazard of Surface Faulting in a Single Fault Zone", in Seismotectonic Hazard Evaluation of the Clyde Dam Site, NZ Geological Survey Report EG 375.

Seed, H.B., Wong, R.T., Idriss, I.M., and Tokimatsu, K., (1984), Moduli and Damping Factors for Dynamic Analysis of Cohesionless Soils, Rep. UCB/EERC - 84/14, Earthq. Eng. Res. Center, Berkeley.

Smith, W.D. and Berryman, K. (1983) "Revised Estimates of Earthquake Hazard in New Zealand", Bulletin, N.Z. Nat. Soc. Earthq. Eng. Vol. 4, pp. 259-272.

Sun, J.I., Golesorkhi, R., and Seed, H.B., (1988), Dynamic Moduli and Damping Ratios for Cohesive Soils, Rep. UCB/EERC - 88/15, Earthq. Eng. Res. Center, Berkeley. 